Check for updates

Cite this: RSC Adv., 2018, 8, 39749

\title{
Hierarchical nanostructures of nitrogen-doped molybdenum sulphide for supercapacitors $\uparrow$
}

\author{
Chaitanya Kanade, (D) ab Sudhir Arbuj, ${ }^{\mathrm{c}}$ Kaluram Kanade, ${ }^{\mathrm{d}}$ Ki Seok Kim, ${ }^{\mathrm{b}}$ \\ Geun Young Yeom, (D) be Taesung Kim ${ }^{\text {bf }}$ and Bharat Kale (D)*c
}

Flower-like nanostructures of molybdenum disulphide $\left(\mathrm{MoS}_{2}\right)$ have been effectively synthesised by the hydrothermal method and further doped with nitrogen using varying concentrations of urea. The formed hierarchical nanostructures are characterised by spectroscopy as well as electrochemical techniques. The structural analysis confirms the formation of a hexagonal $\mathrm{MoS}_{2}$ crystal structure. The existence of $\mathrm{MoO}_{2} / \mathrm{MoO}_{3} / \mathrm{MoS}_{2}$ composites is also observed after heating $\mathrm{MoS}_{2}$ with a lower urea concentration. Surface morphological analysis of all the prepared compositions shows the appearance of flower-like nanostructures formed by the stacking of 20-80 nanosheets to create individual flower petals. Nitrogen doping shows enhancement in the specific capacitance of $\mathrm{MoS}_{2}$ due to an increase in the electronic conductivity. Furthermore, the specific capacitance is enhanced due to the formation of an $\mathrm{MoO}_{2} /$ $\mathrm{MoO}_{3} / \mathrm{MoS}_{2}$ composite. The highest specific capacitance calculated from the charge-discharge curve for nitrogen-doped $\mathrm{MoS}_{2}$ prepared using $1: 1\left(\mathrm{MoS}_{2}\right.$ : urea) weight ratio is observed at around $129\left(\mathrm{~F} \mathrm{~g}^{-1}\right)$ at $2\left(\mathrm{~A} \mathrm{~g}^{-1}\right)$ specific current. The nitrogen-doped $\mathrm{MoS}_{2}$ demonstrates almost four-fold enhancement in specific capacitance than pristine nano-shaped $\mathrm{MoS}_{2}$.

Received 8th August 2018

Accepted 22nd October 2018

DOI: $10.1039 / \mathrm{c} 8 \mathrm{ra06660d}$

rsc.li/rsc-advances hydroxides. Carbon materials such as active carbon, carbon nanotubes, and graphene are the most commonly used electrode materials owing to their high surface area and electrical conductivity, and they come under the category of double layer capacitors. ${ }^{\mathbf{1 , 5}-7}$ Metal organic frameworks, metal oxides, and metal sulphides/selenides have also been reported as supercapacitor electrodes because of the presence of pseudocapacitance. $^{\mathbf{8 - 1 7}}$ The common strategy to enhance the capacitance of supercapacitors is to form composites using metal oxides and conducting polymers with carbon materials to obtain pseudocapacitance as well as double-layer capacitance.

Molybdenum disulphide $\left(\mathrm{MoS}_{2}\right)$ is a two-dimensional transition metal dichalcogenide that has a layered sheet-like structure. $\mathrm{MoS}_{2}$ acts as a good electrode material due to the presence of both pseudocapacitance and double-layer capacitance. The large surface area of layered $\mathrm{MoS}_{2}$ is responsible for double-layer capacitance, whereas redox reactions at the Mo metal center give rise to pseudocapacitance. Therefore, $\mathrm{MoS}_{2}$ can replace composites of metal oxides and carbon as it has faster intrinsic ionic conductivity than oxides and higher theoretical capacitance than graphite $\left(\sim 700 \mathrm{~F} \mathrm{~cm}^{-3}\right) .{ }^{18}$ There are only few investigations on $\mathrm{MoS}_{2}$ as an electrode material for electrochemical applications. ${ }^{10,19,20}$ Some of the reports include doping and composite formation of $\mathrm{MoS}_{2}$ with graphene/nitrogen-doped graphene for supercapacitor and battery applications. ${ }^{21-26}$

The main difficulty in using $\mathrm{MoS}_{2}$ electrode in supercapacitor applications is its low rate performance and capacity fading. ${ }^{25}$ The use of nanomaterials and doped materials can
School of Mechanical Engineering, Sungkyunkwan University, Suwon 440-746, $\dagger$ Electronic supplementary information (ESI) available. See DOI: 10.1039/c8ra06660d
'Indian Institute of Science Education and Research, Pune (IISER Pune), Pashan Road, Pune-411008, India

Suwon 440-746, Korea

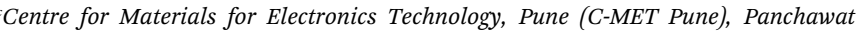
Road, Pashan Pune-411008, India. E-mail: bbkale@cmet.gov.in

Yashantrao Chavan Institute of Science, Satara-415001, India

${ }^{e}$ School of Advanced Materials Science and Engineering, Sungkyunkwan University, Suwon, 16419, South Korea 
enhance the electrochemical performance of $\mathrm{MoS}_{2}$ and help overcome these capacitance problems. There are reports demonstrating enhancement in the electronic properties of $\mathrm{MoS}_{2}$ by doping with transition metals. ${ }^{27,28}$ Nevertheless, nonmetal doping of $\mathrm{MoS}_{2}$ that increases supercapacitor performance has not yet been reported. Nitrogen-doped graphene has shown enhanced performance for supercapacitors and other energy storage devices. ${ }^{\mathbf{2 9 - 3 3}}$ In the case of graphene, defects improve the storage capacity of the graphene electrode but decrease its conductivity; therefore, the overall performance of the graphene electrode decreases. Nitrogen doping helps to improve this decreased performance by enhancing the conductivity. ${ }^{\mathbf{3 0 - 3 2}} \mathrm{MoS}_{2}$ nanosheets are similar to graphene sheets; therefore, nitrogen-doped $\mathrm{MoS}_{2}$ can be expected to show enhanced performance as an electrode material for supercapacitors.

In this regard, for the first time, we report the synthesis of $\mathrm{MoS}_{2}$ and nitrogen-doped $\mathrm{MoS}_{2}$ nanosheets as electrode materials for supercapacitor applications using a hydrothermal route. The increase in nitrogen doping in $\mathrm{MoS}_{2}$ shows marginal increase in specific capacitance due to enhancement in electronic conductivity.

\section{Experimental}

\section{Chemicals}

Ammonium heptamolybdate tetrahydrate, thiourea, urea, and sulphuric acid were purchased from Sigma Aldrich and used as such without further purification.

\section{Synthesis of $2 \mathrm{H}-\mathrm{MoS}_{2}$}

The hydrothermal method was used to synthesize semiconducting hexagonal molybdenum disulphide nanostructures. In a typical experimental procedure, ammonium heptamolybdenate and thiourea were used as molybdenum and sulphur precursors, respectively, to synthesize $\mathrm{MoS}_{2}$. A mixture of ammonium heptamolybdenate and thiourea in $60 \mathrm{ml}$ of water was prepared by keeping the molar ratio of Mo : S as $1: 8$. Then, this mixture was transferred to a Teflon-lined stainless steel autoclave. The sealed autoclave was kept at $200{ }^{\circ} \mathrm{C}$ for $24 \mathrm{~h}$ in a hot air oven. The obtained reaction product was washed with water and subsequently with ethanol. This powder was dried in a vacuum oven at $50{ }^{\circ} \mathrm{C}$ for $5 \mathrm{~h}$ and used for further process.

\section{Nitrogen doping of $\mathrm{MoS}_{2}$}

The synthesised $2 \mathrm{H}-\mathrm{MoS}_{2}$ powder was heated in a tube furnace under a nitrogen environment at $400{ }^{\circ} \mathrm{C}$ for $4 \mathrm{~h}$. The obtained product was termed as $\mathrm{MoS}_{2}-400$. Furthermore, to dope with nitrogen, $\mathrm{MoS}_{2}-400$ was mixed with urea in weight ratios of $1: 1$ and $1: 5$ and subsequently heated in a tube furnace at $400{ }^{\circ} \mathrm{C}$ for $30 \mathrm{~min}$ under a nitrogen environment; the obtained products were termed as $\mathrm{MoS}_{2}-\mathrm{N} 1$ and $\mathrm{MoS}_{2}-\mathrm{N} 5$, respectively.

\section{Characterisation}

As-synthesized $\mathrm{MoS}_{2}, \mathrm{MoS}_{2}-400, \mathrm{MoS}_{2}-\mathrm{N} 1$ and $\mathrm{MoS}_{2}$-N5 nanostructures were characterized by different spectroscopic techniques. The phase purity of the materials was determined by X-ray diffraction (XRD) using a Bruker AXS D8 Advance powder X-ray diffractometer with $\mathrm{Cu} \mathrm{K} \alpha$ radiation $(\lambda=1.5417$ $\AA)$. The diffraction patterns were recorded in the range of $2 \theta\left(10^{\circ}\right.$ to $80^{\circ}$ ) with a step size of $0.01^{\circ}$. Raman spectra were recorded using Jobin Yvon HORIBA LabRAM HR visible micro Raman system, employing a He-Ne laser operating at $632.8 \mathrm{~nm}$ as the source in the backscattering mode. The morphology of the materials was studied by scanning electron microscopy with a Zeiss ${ }^{\mathrm{TM}}$ Ultra Plus field-emission scanning electron microscope (FESEM) equipped with an energy-dispersive X-ray (EDAX) spectrometer. Field emission transmission electron microscopy (FETEM, JEOL, JEM-2200FS) operated at $200 \mathrm{keV}$ was used to obtain the morphology and SAED pattern for synthesised $\mathrm{MoS}_{2}$ nanomaterials. X-ray photoelectron spectroscopy (XPS) of the prepared $\mathrm{MoS}_{2}$ materials was performed with MultiLab 2000, Thermo VG with $\mathrm{Mg} \mathrm{K} \alpha$ X-ray source to determine the chemical compositions of the samples.

Electrochemical measurements were carried out using threeelectrode cell configuration on Autolab PGSTAT302N. Cyclic voltammetry measurements of the $\mathrm{MoS}_{2}$ electrodes were performed in $\mathrm{H}_{2} \mathrm{SO}_{4}$ electrolyte at different scan rates over a potential window from -0.2 to $+0.8 \mathrm{~V}$ with $\mathrm{MoS}_{2}$ as the working electrode, platinum as the counter electrode and $\mathrm{Ag} /$ $\mathrm{AgCl}$ as the reference electrode. The loaded mass of the synthesised $\mathrm{MoS}_{2}$ on the working electrode was around 3-4 mg for each sample. Charge-discharge characterisations were performed at different specific currents within the potential window from -0.2 to $+0.8 \mathrm{~V}$ with a similar experimental setup. Electrochemical impedance spectroscopy (EIS) measurements were carried out in the range from $100 \mathrm{MHz}$ to $100 \mathrm{kHz}$ with an AC amplitude of $10 \mathrm{mV}$ in $1 \mathrm{M} \mathrm{H}_{2} \mathrm{SO}_{4}$ electrolyte.

\section{Results and discussion}

The XRD patterns of synthesised $\mathrm{MoS}_{2}$ and nitrogen-doped $\mathrm{MoS}_{2}$ nanostructures are depicted in Fig. 1(a-d) for $2 \theta$ range from $10^{\circ}$ to $80^{\circ}$. The intense and broad reflection peaks confirm the formation of the $2 \mathrm{H}-\mathrm{MoS}_{2}$ nanostructure for all the prepared compositions. The XRD pattern of the synthesised $\mathrm{MoS}_{2}$

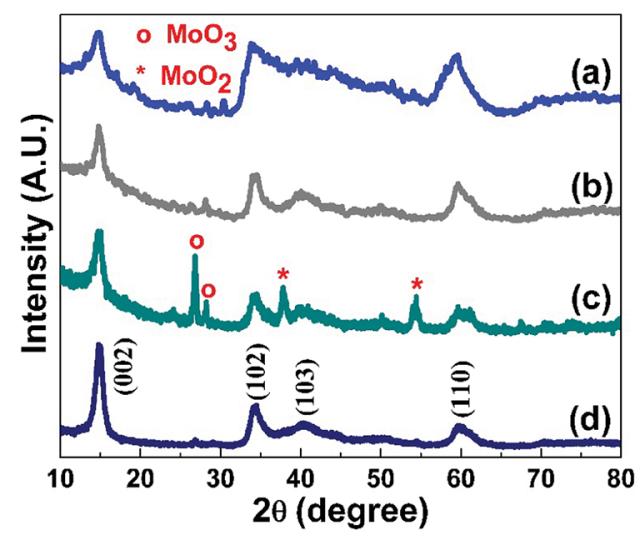

Fig. 1 X-ray diffraction patterns for $\mathrm{MoS}_{2}$ (a), $\mathrm{MoS}_{2}-400$ (b), MoS $2-\mathrm{N} 1$ (c), and $\mathrm{MoS}_{2}-\mathrm{N} 5$ (d). 
matches the standard $\mathrm{MoS}_{2}$ pattern (JCPDS ICDD no. 37-1492). The observed XRD peaks at $2 \theta=14.53^{\circ}, 32.67^{\circ}, 33.50^{\circ}, 35.87^{\circ}$, $39.53^{\circ}, 58.33^{\circ}$, and $60.14^{\circ}$ correspond to (002), (100), (101), (102), (103), (110), and (008) $h k l$ planes of hexagonal $\mathrm{MoS}_{2}$. The XRD patterns of nitrogen-doped $\mathrm{MoS}_{2}$ nanostructures $\left(\mathrm{MoS}_{2}-\mathrm{N} 1\right.$ and $\mathrm{MoS}_{2}$-N5) are compared with the XRD patterns of assynthesised $\mathrm{MoS}_{2}$ and $\mathrm{MoS}_{2}-400$, as depicted in Fig. 1(a-d). After nitrogen doping, there is slight change in the XRD peak intensity, but the peak positions remain the same. In the case of $\mathrm{MoS}_{2}-\mathrm{N} 1$ sample, the formation of $\mathrm{MoO}_{2}$ and $\mathrm{MoO}_{3}$ along with $\mathrm{MoS}_{2}$ is observed; this clearly indicates the formation of $\mathrm{MoO}_{2} /$ $\mathrm{MoO}_{3} / \mathrm{MoS}_{2}$ nanocomposites. The reflection peaks due to $\mathrm{MoO}_{2}$ and $\mathrm{MoO}_{3}$ match with JCPDS no. 32-0671 and 47-1081, respectively. Composite formation is observed for $\mathrm{MoS}_{2}-\mathrm{N} 1$ sample only. Even though the synthesis methods for $\mathrm{MoS}_{2}-\mathrm{N} 1$ and $\mathrm{MoS}_{2}$-N5 are similar, the conversion of $\mathrm{MoS}_{2}$ to $\mathrm{MoO}_{2} / \mathrm{MoO}_{3}$ is different, as seen in the XRD pattern. In the case of $\mathrm{MoS}_{2}-\mathrm{N} 1$, the amount of carbon available (in the form of urea) to react with oxygen to form carbon dioxide is low as compared to that for $\mathrm{MoS}_{2}-\mathrm{N} 5$. Therefore, for $\mathrm{MoS}_{2}-\mathrm{N} 1$, the remaining oxygen reacts with $\mathrm{MoS}_{2}$ to form molybdenum oxide. Thus, we observe difference in oxide formations for $\mathrm{MoS}_{2}-\mathrm{N} 1$ and $\mathrm{MoS}_{2}-\mathrm{N} 5$.

The broadening of the XRD peak decreases, indicating a more crystalline structure for nitrogen-doped $\mathrm{MoS}_{2}$. The broad XRD peaks confirm that the prepared structures are still in the nanoscale even after heating at $400{ }^{\circ} \mathrm{C}$ for nitrogen doping. Furthermore, structural analysis of prepared $\mathrm{MoS}_{2}$ and nitrogen-doped $\mathrm{MoS}_{2}$ are conducted by Raman spectroscopy. Fig. 2(a-d) shows the Raman scattering curves for $\mathrm{MoS}_{2}, \mathrm{MoS}_{2^{-}}$ 400, $\mathrm{MoS}_{2}-\mathrm{N} 1$ and $\mathrm{MoS}_{2}$-N5 in the range from 350 to $450 \mathrm{~cm}^{-1}$. The two peaks correspond to in-plane $\left(\mathrm{E}_{2 \mathrm{~g}}^{1}\right)$ and out-of-plane $\left(\mathrm{A}_{1 \mathrm{~g}}\right)$ vibrations at 378 and $403 \mathrm{~cm}^{-1}$ for the synthesised $\mathrm{MoS}_{2}$ materials. These two characteristic Raman peaks confirm the formation of nanoscale $\mathrm{MoS}_{2}$. There is negligible change in the peak separation between $\mathrm{A}_{1 \mathrm{~g}}$ and $\mathrm{E}_{2 \mathrm{~g}}^{1}$ for nitrogen-doped $\mathrm{MoS}_{2}$ compare to that for pristine $\mathrm{MoS}_{2}$. The $\mathrm{A}_{1 \mathrm{~g}} / \mathrm{E}_{2 \mathrm{~g}}^{1}$ ratios for $\mathrm{MoS}_{2}$, $\mathrm{MoS}_{2}$ 400, $\mathrm{MoS}_{2}-\mathrm{N} 1$ and $\mathrm{MoS}_{2}$-N5 are 2.3, 2.7, 2.2 and 2.1,

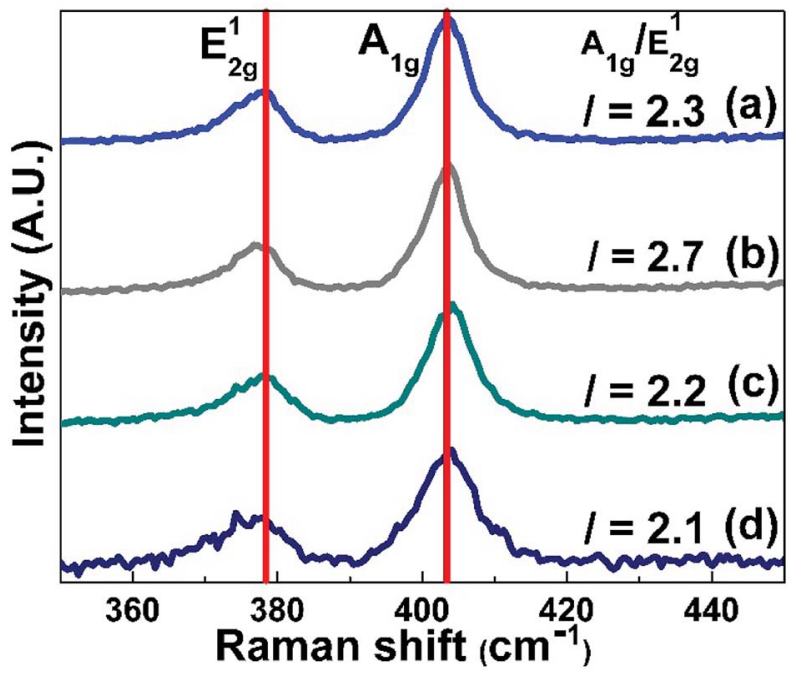

Fig. 2 Raman spectra for $\mathrm{MoS}_{2}$ (a), $\mathrm{MoS}_{2}-400$ (b), MoS $-\mathrm{N1}$ (c), and $\mathrm{MoS}_{2}-\mathrm{N} 5$ (d). respectively. The $\mathrm{A}_{1 \mathrm{~g}} / \mathrm{E}_{2 \mathrm{~g}}^{1}$ ratio decreases from $\mathrm{MoS}_{2} 400$ to $\mathrm{MoS}_{2^{-}}$ $\mathrm{N} 5$, confirming that the defect edge sites of $\mathrm{MoS}_{2}$ are occupied by nitrogen species.

The surface and morphological studies of prepared $\mathrm{MoS}_{2}$ nanomaterials were carried out using FESEM and TEM analysis. The magnified images of $\mathrm{MoS}_{2}, \mathrm{MoS}_{2}-400, \mathrm{MoS}_{2}-\mathrm{N} 1$, and $\mathrm{MoS}_{2}$ $\mathrm{N} 5$ are shown in Fig. $3(\mathrm{a}-\mathrm{d})$. The formation of flower-like nanostructures is observed in the prepared $\mathrm{MoS}_{2}$ samples. The flower-like nanostructure is formed by stacking of nanosheets up to 20-50 $\mathrm{nm}$ thickness. As exhibited in Fig. 3(b), $\mathrm{MoS}_{2}$ 400 shows growth and an opening of nanosheets into flowershaped nanostructures. The nitrogen doping in $\mathrm{MoS}_{2}$ nanostructures results in rupturing of nanosheets in $\mathrm{MoS}_{2}-\mathrm{N} 1$ and $\mathrm{MoS}_{2}-\mathrm{N} 5$, as shown in Fig. 3(c and d). In the case of $\mathrm{MoS}_{2}-\mathrm{N} 1$ sample, the existence of rods and rectangular plates is observed, which may be due to the formation of $\mathrm{MoO}_{2}$ and $\mathrm{MoO}_{3}$ nanostructures (ESI, Fig. S1†). Further detailed study related to oxide formation is confirmed by TEM analysis.

Microstructural analysis of prepared $\mathrm{MoS}_{2}$ nanomaterials was conducted using TEM analysis, and the images are shown in Fig. 4. Fig. 4 shows the TEM images of $\mathrm{MoS}_{2}$ (a and e), $\mathrm{MoS}_{2}$ 400 (b and f), $\mathrm{MoS}_{2}$-N1 (c and g) and $\mathrm{MoS}_{2}$-N5 (d and h). The layered structure of prepared $\mathrm{MoS}_{2}$ is confirmed from TEM analysis. TEM clearly indicates the formation of flower-like morphology consisting of stacked nanosheets as flower petals, and this is consistent with the FESEM results. The size of petals in the as-synthesised $\mathrm{MoS}_{2}$ is between 20 and $50 \mathrm{~nm}$; for $\mathrm{MoS}_{2}$ 400 , the size is between 20 and $80 \mathrm{~nm}$. However, it is observed that the petal size range is decreased to $20-40 \mathrm{~nm}$ in the case of $\mathrm{MoS}_{2}$-N1. Every petal is formed by stacking of two-dimensional $\mathrm{MoS}_{2}$ nanosheets, as can be seen in Fig. 4(e-h). As discussed in the FESEM analysis, an opening of the nanosheets in $\mathrm{MoS}_{2}-400$ can be seen in Fig. 4(f) as the interlayer distance increases from $\sim 6.9 \AA$ to $\sim 7.5 \AA$ compared with that observed for pristine $\mathrm{MoS}_{2}$. As discussed in XRD and FESEM analysis, the formation of $\mathrm{MoO}_{2} / \mathrm{MoO}_{3} / \mathrm{MoS}_{2}$ nanocomposites can be seen in Fig. $4(\mathrm{~g})$ for the $\mathrm{MoS}_{2}-\mathrm{N} 1$ nanomaterial. In the case of $\mathrm{MoS}_{2}-\mathrm{N} 5$, such composite formation is not observed. The selected area electron

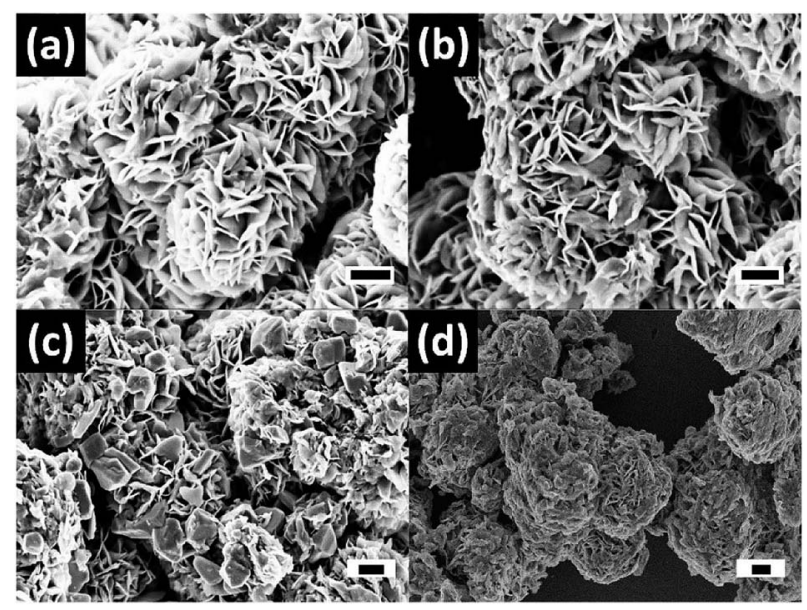

Fig. 3 FESEM images of low and high magnification for $\mathrm{MOS}_{2}$ (a), $\mathrm{MoS}_{2}-400$ (b), $\mathrm{MoS}_{2}-\mathrm{N1}$ (c), and $\mathrm{MoS}_{2}-\mathrm{N} 5$ (d). Scale bars $400 \mathrm{~nm}$ (black). 


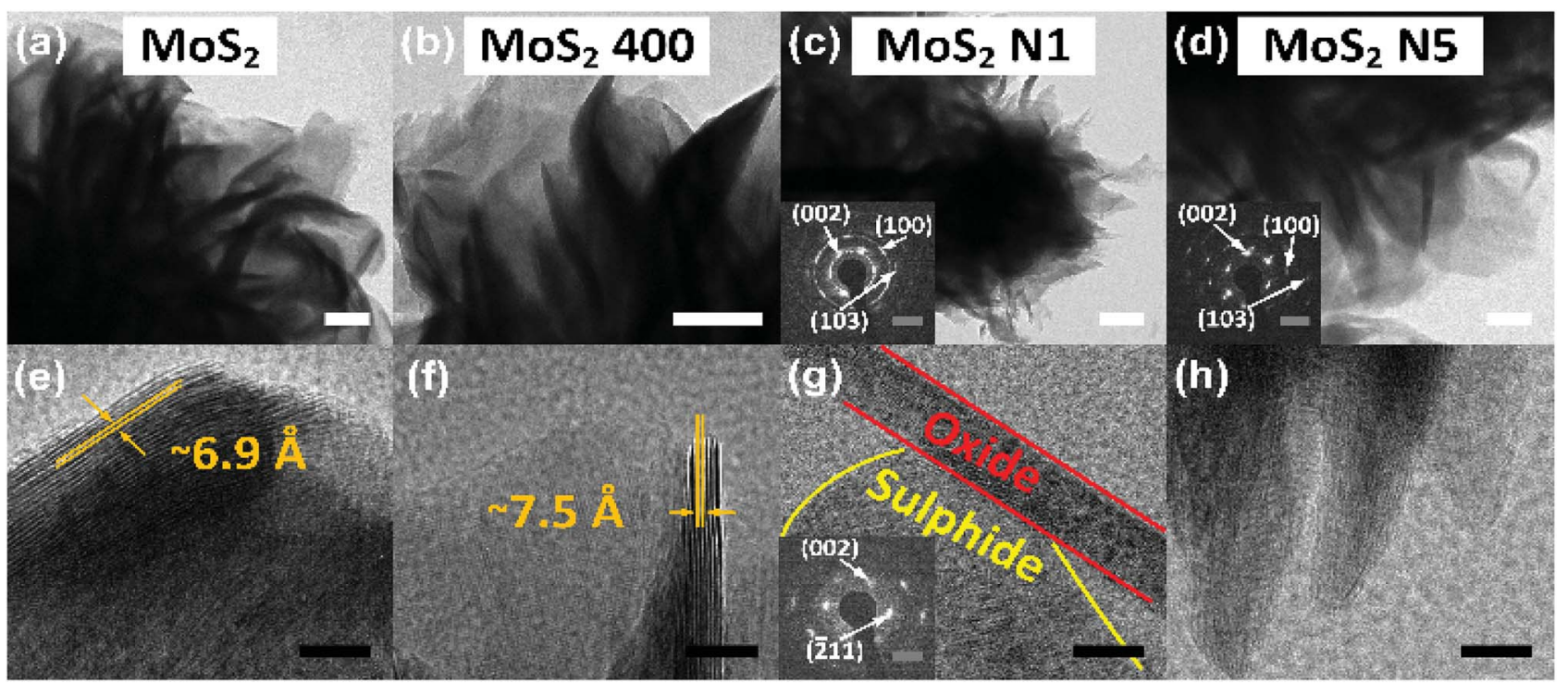

Fig. 4 TEM images for flower petals and stacked nanosheets for (a and b) $\mathrm{MoS}_{2}$, (c and d) $\mathrm{MoS}_{2}-400$, (e and f) MoS $-\mathrm{N1}$, and (g and h) MoS $\mathrm{S}_{2}-\mathrm{N} 5$. Scale bars: $100 \mathrm{~nm}$ (white) and $5 \mathrm{~nm}$ (black). Insets show the SAED ring patterns for (e) $\mathrm{MoS}_{2}-\mathrm{N} 1 \mathrm{flower}$ petal, (f) MoS $-\mathrm{N} 1 \mathrm{rod} / \mathrm{plates}$ and (g) $\mathrm{MoS}_{2}$-N5 flower. Inset scale bars, $5 \mathrm{~nm}^{-1}$ (grey).

diffraction (SAED) pattern confirms that the rod- and plate-like structure shows the oxide phase, whereas the layered flowers exhibit the sulphide phase of nanomaterials. The insets in Fig. 4(c and g) show the SAED patterns for flowers and rods of $\mathrm{MoS}_{2}$-N1 nanomaterials, respectively, whereas the inset in Fig. 4(d) shows the SAED pattern for the flowers of $\mathrm{MoS}_{2}$-N5. The SAED pattern demonstrates intense patterns for different crystallographic planes. The $h k l$ planes (002), (100), and (103) show the sulphide phase for the SAED patterns of $\mathrm{MoS}_{2}-\mathrm{N} 1$ and $\mathrm{MoS}_{2}$-N5 and are marked in the insets of Fig. 4(c and d). The (002) and ( $\overline{2} 11) h k l$ planes of the oxide phase of $\mathrm{MoS}_{2}-\mathrm{N} 1$ are shown in Fig. $4(\mathrm{~g})$. The $h k l$ planes and their $d$ spacing exactly match with those calculated from the XRD pattern. To confirm the formation of oxide/sulphide nanocomposites, elemental mapping is carried out, and the results are shown in the ESI (Fig. S2 $\dagger$ ). The elemental mapping clearly indicates the presence of oxide along with sulphides. Overall, the TEM analysis shows that the results are consistent with the XRD and FESEM results.

X-ray photoelectron spectroscopy (XPS) of the prepared $\mathrm{MoS}_{2}$ samples was conducted to check the elemental composition of the materials. Fig. 5 shows the XPS spectra for $\mathrm{MoS}_{2}(\mathrm{a}), \mathrm{MoS}_{2}-400$ (b), $\mathrm{MoS}_{2}-\mathrm{N} 1$ (c) and $\mathrm{MoS}_{2}-\mathrm{N} 5$ (d) for binding energies ranging from $394 \mathrm{eV}$ to $408 \mathrm{eV}$. The N 1s peak around $399.1 \mathrm{eV}$ confirms that nitrogen is present in $\mathrm{MoS}_{2}-\mathrm{N} 1$ and $\mathrm{MoS}_{2}-\mathrm{N} 5$ nanomaterials. Mo $3 \mathrm{p}_{3 / 2}$ can be observed at $395.5 \mathrm{eV}$ in all synthesised materials. The XPS spectra for the Mo 3d peak and S 2p peak and survey scans of the prepared $\mathrm{MoS}_{2}$ nanomaterials are provided in the ESI (Fig. S3†). The sulphur (S) to molybdenum (Mo) atomic percentage ratios for $\mathrm{MoS}_{2}-\mathrm{N} 1$ and $\mathrm{MoS}_{2}-\mathrm{N} 5$ are found to be 1.16 and 1.35, respectively. The deviation from the ideal stoichiometric ratio ( $\mathrm{S}: \mathrm{Mo}$ ) indicates the amounts of oxygen and nitrogen present in $\mathrm{MoS}_{2}-\mathrm{N} 1$ and $\mathrm{MoS}_{2}-\mathrm{N} 5$ nanomaterials. The nitrogen-to-sulphur atomic percentage ratios are found to be 1.83 and 2.19 for $\mathrm{MoS}_{2}-\mathrm{N} 1$ and $\mathrm{MoS}_{2}-\mathrm{N} 5$, respectively. The ratio confirms that the amount of nitrogen present in the $\mathrm{MoS}_{2}-\mathrm{N} 5$ nanomaterial is higher than that in $\mathrm{MoS}_{2}-\mathrm{N} 1$ nanostructures.

The electrochemical performances of prepared $\mathrm{MoS}_{2}$ nanostructures are studied by cyclic voltammetry (CV) and galvanostatic charge-discharge (GCD) curves using a three-electrode system. The CV curves of the prepared $\mathrm{MoS}_{2}$ nanomaterials were recorded in $1 \mathrm{M} \mathrm{H}_{2} \mathrm{SO}_{4}$ electrolyte for scan rates of 5, 20, 100 , and $200 \mathrm{mV} \mathrm{s}^{-1}$. The nearly rectangular and symmetric shape of the CV curves can be seen in Fig. 6(a) for as-synthesised $\mathrm{MoS}_{2}$. In Fig. 6(a), the oxidation and reduction peaks for Mo metal centre can be seen at lower step sizes $\left(5 \mathrm{mV} \mathrm{s}^{-1}\right.$ and $20 \mathrm{mV}$ $\mathrm{s}^{-1}$ ). These peaks lead to pseudocapacitance in the $\mathrm{MoS}_{2}$ materials. The non-regular rectangular CV curve shows electrochemical double layer capacitance in the synthesised $\mathrm{MoS}_{2}$ material. Fig. 6(b) shows a comparison of the CV curves at

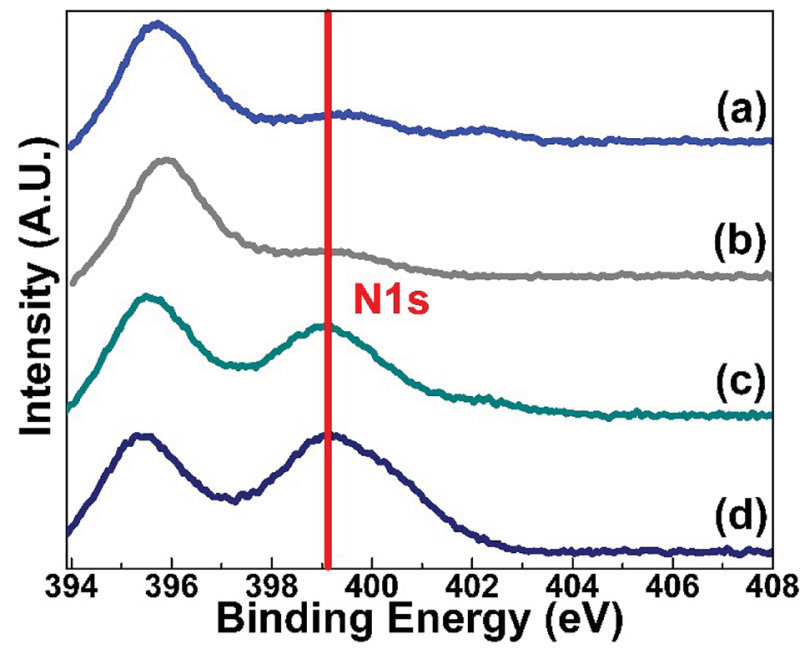

Fig. 5 XPS spectra for $\mathrm{MoS}_{2}$ (a), $\mathrm{MoS}_{2}-400$ (b), $\mathrm{MoS}_{2}-\mathrm{N1}$ (c) and $\mathrm{MoS}_{2}-$ $\mathrm{N} 5$ (d) for binding energies ranging from $392 \mathrm{eV}$ to $409 \mathrm{eV}$. 
(a)

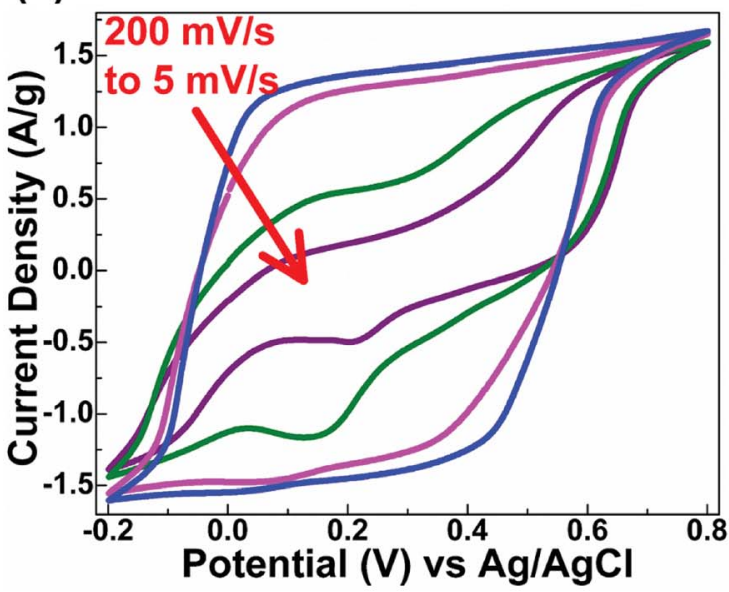

(b)

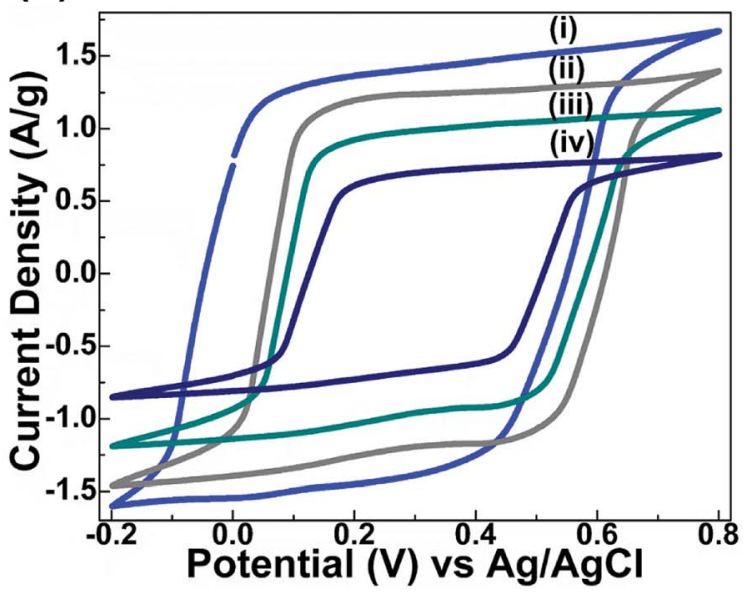

Fig. 6 (a) Cyclic voltammetry (CV) curves for as-synthesised $\mathrm{MoS}_{2}$ nanomaterial for scan rates of $5 \mathrm{mV} \mathrm{s}^{-1}, 20 \mathrm{mV} \mathrm{s}^{-1}, 100 \mathrm{mV} \mathrm{s}$, and $200 \mathrm{mV}$ $\mathrm{s}^{-1}$ (b) CV curves for (i) $\mathrm{MoS}_{2}$, (ii) $\mathrm{MoS}_{2}-400$, (iii) $\mathrm{MoS}_{2}-\mathrm{N} 1$, and (iv) $\mathrm{MoS}_{2}-\mathrm{N} 5$ at scan rate of $200 \mathrm{mV} \mathrm{s}^{-1}$.

$200 \mathrm{mV} \mathrm{s}^{-1}$ for $\mathrm{MoS}_{2}, \mathrm{MoS}_{2}-400, \mathrm{MoS}_{2}-\mathrm{N} 1$, and $\mathrm{MoS}_{2}-\mathrm{N} 5$. Furthermore, the capacitive performances of prepared $\mathrm{MoS}_{2}$ nanostructures are evaluated by galvanostatic charge-discharge curves measured at different current densities $(2,3,4$, and $\left.5 \mathrm{~A} \mathrm{~g}^{-1}\right)$ in $1 \mathrm{M} \mathrm{H}_{2} \mathrm{SO}_{4}$ electrolyte. The specific capacitance $\left(C_{\mathrm{s}}\right)$ values of the prepared $\mathrm{MoS}_{2}$ nanomaterials are calculated from the GCD curves using the following equation:

$$
C_{\mathrm{s}}=(I \times \Delta t) /(m \times \Delta V)
$$

Here, $I$ is the discharge current (A), $\Delta t$ is the discharge time (s), $m$ is mass of active material $(\mathrm{g})$, and $\Delta V$ is the potential window (V) for discharge time. The calculated values of specific capacitance are higher for lower current densities and subsequently decrease for higher current densities. This is a common observation in electrode materials due to charge resistive behaviour at higher current values. The specific capacitance values are higher for $\mathrm{MoS}_{2} \mathrm{~N} 1$ in comparison with those for other prepared $\mathrm{MoS}_{2}$ materials from the GCD curves. The specific capacitance values for $\mathrm{MoS}_{2}-\mathrm{N} 1$ are $129,99,88$, and $76 \mathrm{~F}$ $\mathrm{g}^{-1}$ in $1 \mathrm{M} \mathrm{H}_{2} \mathrm{SO}_{4}$ electrolyte at specific currents of $2,3,4$, and $5 \mathrm{~A} \mathrm{~g}^{-1}$, respectively. The specific capacitance values at $2 \mathrm{~A} \mathrm{~g}^{-1}$ for $\mathrm{MoS}_{2}, \mathrm{MoS}_{2}-400$, and $\mathrm{MoS}_{2}-\mathrm{N} 5$ are 34.9, 35.6, and $74.4 \mathrm{~F} \mathrm{~g}^{-1}$, respectively. Fig. 7 shows the comparison between the calculated specific capacitance values at different specific currents for $\mathrm{MoS}_{2}, \mathrm{MoS}_{2}-400, \mathrm{MoS}_{2}-\mathrm{N} 1$, and $\mathrm{MoS}_{2}$-N5 .

The electrochemical results show the enhanced specific capacitance for $\mathrm{MoS}_{2}-\mathrm{N} 1$ and $\mathrm{MoS}_{2}-\mathrm{N} 5$ as compared with that for $\mathrm{MoS}_{2}$. This confirms that nitrogen doping increases the capacitance of $\mathrm{MoS}_{2}$ material. $\mathrm{MoS}_{2}$-N1 shows almost 3.5 times improvement in capacitance value relative to $\mathrm{MoS}_{2}$. $\mathrm{MoS}_{2}-\mathrm{N} 1$ has higher capacitance than $\mathrm{MoS}_{2}$-N5 due to the presence of $\mathrm{N}$ doped $\mathrm{MoO}_{2} / \mathrm{MoO}_{3} / \mathrm{MoS}_{2}$ composite material. The main reason behind the increase in specific capacitance can be correlated with the structure of the prepared nanomaterials, the composition and their electronic conductivities.

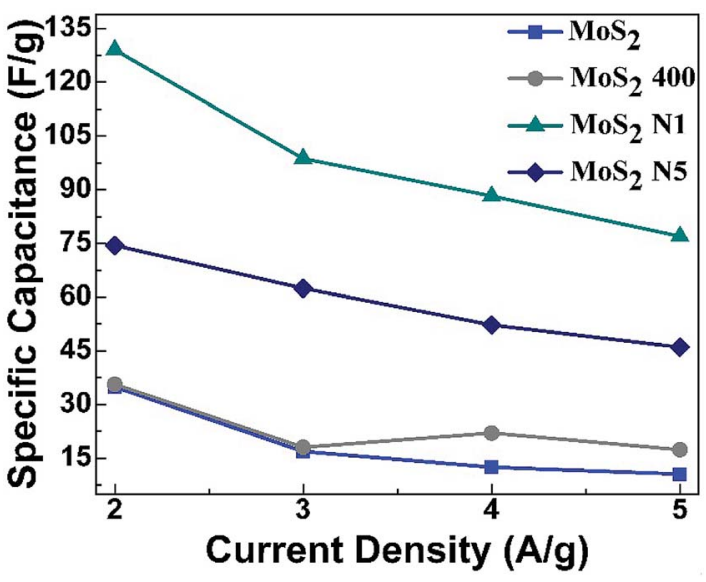

Fig. 7 The comparison between specific capacitances $\left(\mathrm{F} \mathrm{g}^{-1}\right)$ of $\mathrm{MoS}_{2}$, $\mathrm{MoS}_{2}-400, \mathrm{MoS}_{2}-\mathrm{N} 1$, and $\mathrm{MoS}_{2}-\mathrm{N} 5$ vs. specific current $\left(\mathrm{A} \mathrm{g}^{-1}\right)$.

Furthermore, electrochemical impedance spectroscopy (EIS) is performed to understand the charge kinetics and supercapacitor behaviour of prepared $\mathrm{MoS}_{2}$ nanomaterials. Fig. 8(a) shows the Nyquist plots of $\mathrm{MoS}_{2}, \mathrm{MoS}_{2}-400, \mathrm{MoS}_{2}-\mathrm{N} 1$ and $\mathrm{MoS}_{2}-$ N5. The prepared $\mathrm{MoS}_{2}$ nanostructures show the supercapacitor feature, i.e., a semicircle at higher frequencies and a straight line at the lower frequency region. The intercept on the real axis is ascribed to the equivalent series resistance $\left(R_{\mathrm{s}}\right)$, and the diameter of the semicircle corresponds to the charge transfer resistance $\left(R_{\mathrm{ct}}\right)$ in the electrode/electrolyte system. The $R_{\mathrm{s}}$ values for $\mathrm{MoS}_{2}, \mathrm{MoS}_{2}-400, \mathrm{MoS}_{2}-\mathrm{N} 1$ and $\mathrm{MoS}_{2}-\mathrm{N} 5$ are 2.16, 2.63, 1.89 and $1.16 \Omega$, respectively. Nitrogen doping decreases the $R_{\mathrm{s}}$ values for $\mathrm{MoS}_{2}-\mathrm{N} 1$ and $\mathrm{MoS}_{2}$-N5. This confirms that nitrogen doping has enhanced the electrical conductivity of $\mathrm{MoS}_{2}$. The oxide/sulphide composite in $\mathrm{MoS}_{2}$-N1 may be responsible for the higher $R_{\mathrm{ct}}$ value (2.2 $\Omega$ ) in the Nyquist plot compared to that for other $\mathrm{MoS}_{2}$ nanomaterials $(<1.5 \Omega)$. The low frequency straight line parallel to the imaginary axis shows the capacitive behaviour of $\mathrm{MoS}_{2}$ nanomaterials (Fig. 8(a)). The highest slope 
(a)

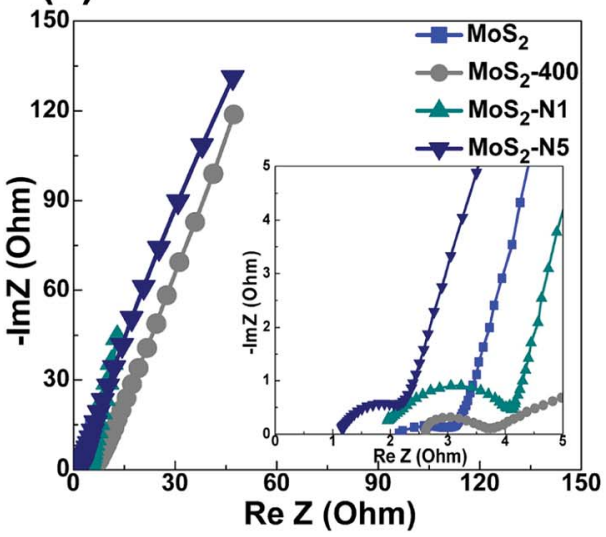

(b)

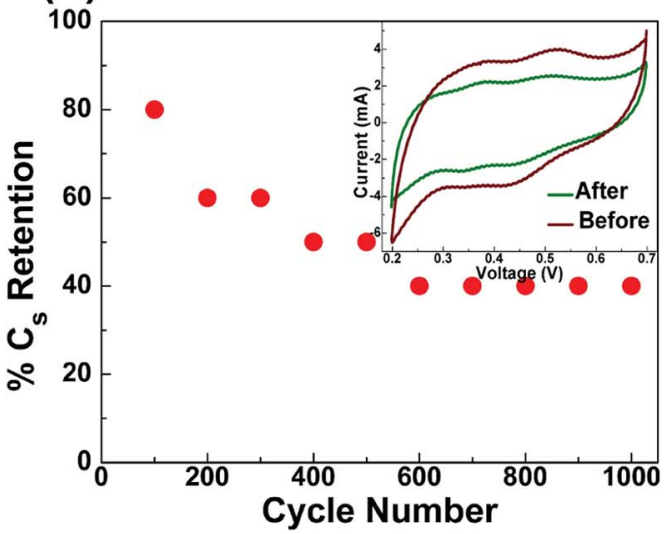

Fig. 8 (a) Nyquist Plots of $\mathrm{MoS}_{2}, \mathrm{MoS}_{2}-400, \mathrm{MoS}_{2}-\mathrm{N} 1$ and $\mathrm{MoS}_{2}-\mathrm{N} 5$; (inset shows the high frequency region of (a)). (b) \% $\mathrm{C}_{\mathrm{s}}$ retention vs. cycle number for $\mathrm{MoS}_{2}-\mathrm{N} 1$ electrode; (inset shows $\mathrm{CV}$ at $100 \mathrm{mV}$ scan rate before and after 1000 cycles).

Table 1 The comparison of specific capacitance of reported $\mathrm{MoS}_{2}$ only materials at specific current and electrolyte. (The contents in the table are arranged in decreasing order of specific current for comparison.)

\begin{tabular}{|c|c|c|c|c|c|}
\hline Sr. no. & Method & Phase & Morphology & Specific capacitance $\left(\mathrm{F} \mathrm{g}^{-1}\right)$ & Reference \\
\hline 1 & Hydrothermal & $2-\mathrm{H}$ & Flowers & 129 at $2 \mathrm{~A} \mathrm{~g}^{-1}$ in $1 \mathrm{M} \mathrm{H}_{2} \mathrm{SO}_{4}$ & This work \\
\hline 2 & Two step hydrothermal & $2-\mathrm{H}$ & 3D flower & 168 at $1 \mathrm{~A} \mathrm{~g}^{-1}$ in $1 \mathrm{M} \mathrm{KCl}$ & 34 \\
\hline 4 & Hydrothermal & $2-\mathrm{H}$ & Flower-like & $129.2 \mathrm{~F} \mathrm{~g}^{-1}$ at $1 \mathrm{~A} \mathrm{~g}^{-1}$ in $1 \mathrm{M} \mathrm{Na}_{2} \mathrm{SO}_{4}$ & 36 \\
\hline 5 & CVD & $2-\mathrm{H}$ & Nanowall & $100 \mathrm{~F} \mathrm{~g}^{-1}$ at $1 \mathrm{mV} \mathrm{s}^{-1}$ in $0.5 \mathrm{M} \mathrm{H}_{2} \mathrm{SO}_{4}$ & 37 \\
\hline 6 & Hydrothermal & $2-\mathrm{H}$ & Nanosphere & 122 at $0.5 \mathrm{~A} \mathrm{~g}^{-1}$ in $1 \mathrm{M} \mathrm{Na}_{2} \mathrm{SO}_{4}$ & 18 \\
\hline
\end{tabular}

of the straight line is obtained for $\mathrm{MoS}_{2}-\mathrm{N} 1$, suggesting that $\mathrm{MoS}_{2} \mathrm{~N} 1$ has optimal performance among the prepared $\mathrm{MoS}_{2}$ nanostructures. The EIS measurements also support that nitrogen doping enhances the conductive performance of prepared $\mathrm{MoS}_{2}$ nanostructures.

The cycling stability of $\mathrm{MoS}_{2}-\mathrm{N} 1$ material is studied by cyclic charge-discharge at $1 \mathrm{~A} \mathrm{~g}^{-1}$ current density in $1 \mathrm{M} \mathrm{H}_{2} \mathrm{SO}_{4}$ electrolyte. Fig. 8(b) shows the stability of the prepared $\mathrm{MoS}_{2}-\mathrm{N} 1$ electrode over 1000 cycles. The CV measurements at $100 \mathrm{mV} \mathrm{s}^{-1}$ scan rate are also recorded before and after 1000 cycles. The CV analysis shows almost $70 \%$ capacitance retention after 1000 cycles. The charge-discharge cycles show $40 \%$ retention in specific capacitance for $\mathrm{MoS}_{2}-\mathrm{N} 1$ after 1000 cycles.

The synthesised $\mathrm{MOS}_{2}-\mathrm{N} 1$ shows similar crystallographic phase and structure to that of reported $\mathrm{MoS}_{2}$ nanostructures. The comparison of specific capacitances of prepared $\mathrm{MoS}_{2}-\mathrm{N} 1$ and reported $\mathrm{MoS}_{2}$ nanostructures at a specific current and electrolyte is depicted in Table 1 . In comparison with the reported $\mathrm{MoS}_{2}$ nanostructures, the synthesised $\mathrm{MOS}_{2}-\mathrm{N} 1$ shows higher specific capacitance at a higher current density, i.e., 129 $\mathrm{F} \mathrm{g}^{-1}$ at $2 \mathrm{~A} \mathrm{~g}^{-1}$ in $1 \mathrm{M}$ of $\mathrm{H}_{2} \mathrm{SO}_{4}$. Fig. 7 confirms that the specific capacitance decreases as the specific current increases. Thus, higher specific capacitance at high current density shows the superiority of $\mathrm{MoS}_{2}-\mathrm{N} 1$ over other reported materials. Therefore, $\mathrm{MoS}_{2}-\mathrm{N} 1$ is a better electrode material because it exhibits higher specific capacitance at higher specific currents compared to reported $2 \mathrm{H}-\mathrm{MoS}_{2}$ materials.

\section{Conclusion}

The successful synthesis of nitrogen-doped $\mathrm{MoS}_{2}$ hierarchical nanostructures was demonstrated by a simple low-cost synthesis method. The structural and morphological characterisation confirmed the formation of flower-like nanostructures of hexagonal $\mathrm{MoS}_{2}$ along with the formation of oxide/ sulphide nanocomposites. $\mathrm{MoS}_{2}-\mathrm{N} 1$ showed specific capacitance of $129 \mathrm{~F} \mathrm{~g}^{-1}$ at a specific current of $2 \mathrm{~A} \mathrm{~g}^{-1}$. The formed nitrogen-doped $\mathrm{MoO}_{2} / \mathrm{MoO}_{3} / \mathrm{MoS}_{2}$ nanocomposites showed four-fold enhancement in specific capacitance than the assynthesised $\mathrm{MoS}_{2}$ nanostructures. These results suggest that nitrogen-doped $\mathrm{MoO}_{2} / \mathrm{MoO}_{3} / \mathrm{MoS}_{2}$ nanocomposites can be promising electrode materials for supercapacitor applications.

\section{Conflicts of interest}

There are no conflicts to declare.

\section{Acknowledgements}

CK would like to acknowledge to the Director of Indian Institute of Science Education and Research, Pune (IISER Pune) for giving the permission to work at Centre for Materials for Electronics Technology, Pune Lab (C-MET Pune). CK would like to thank the BBK group for providing research facilities and platform. CK would like to acknowledge Dr G. Gund group for valuable guidance and help. 


\section{Notes and references}

1 C. Liu, Z. Yu, D. Neff, A. Zhamu and B. Z. Jang, Nano Lett., 2010, 10(12), 4863.

2 J. Zhou, Y. Huang, X. Cao, B. Ouyang, W. Sun, C. Tan, Y. Zhang, Q. Ma, S. Liang, Q. Yan and H. Zhang, Nanoscale, 2015, 7(16), 7035.

3 M. Camara, H. Gualous, F. Gustin and A. Berthon, IEEE Trans. Veh. Technol., 2008, 57(5), 2721.

4 P. Thounthong, S. Rael and B. Davat, J. Power Sources, 2009, 193(1), 376.

5 H. Pan, J. Li and Y. Feng, Nanoscale Res. Lett., 2010, 5(3), 654. 6 L. Zhang and X. Zhao, Chem. Soc. Rev., 2009, 38(9), 2520.

7 Y. Tan and J. Lee, J. Mater. Chem. A, 2013, 1(47), 14814.

8 R. Ramachandran, M. Saranya, P. Kollu, B. Raghupathy, S. Jeong and A. Grace, Electrochim. Acta, 2015, 178-647.

9 X. Xie, K. Huang and X. Wu, J. Mater. Chem. A, 2018, 6, 6754.

10 A. Ramadoss, T. Kim, G. Kim and S. Kim, New J. Chem., 2014, 38(6), 2379.

11 M. Javed, C. Zhang, L. Chen, Y. Xi and C. Hu, J. Mater. Chem. A, 2016, 4(22), 8851.

12 L. Cao, S. Yang, W. Gao, Z. Liu, Y. Gong, L. Ma, G. Shi, S. Lei, Y. Zhang, S. Zhang and R. Vajtai, Small, 2013, 9(17), 2905.

13 N. Choudhary, C. Li, H. Chung, J. Moore, J. Thomas and Y. Jung, ACS Nano, 2016, 10(12), 10726.

14 J. Yang, X. Duan, Q. Qin and W. Zheng, J. Mater. Chem. A, 2013, 1(27), 7880.

15 H. Chauhan, M. Singh, S. Hashmi and S. Deka, RSC Adv., 2015, 5(22), 17228.

16 W. Zhang and K. Huang, Inorg. Chem. Front., 2017, 4, 1602. 17 Z. Zhaia, K. Huanga and X. Wub, Nano Energy, 2018, 47, 89. 18 M. Acerce, D. Voiry and M. Chhowalla, Nat. Nanotechnol., 2015, 10(4), 313.

19 K. Krishnamoorthy, G. Veerasubramani, S. Radhakrishnan and S. Kim, Mater. Res. Bull., 2014, 50, 499.

20 P. Ilanchezhiyan, G. Kumar and T. Kang, J. Alloys Compd., 2015, 634, 104.
21 K. Huang, L. Wang, Y. Liu, Y. Liu, H. Wang, T. Gan and L. Wang, Int. J. Hydrogen Energy, 2013, 38, 14027.

22 B. Xie, Y. Chen, M. Yu, T. Sun, L. Lu, T. Xie, Y. Zhang and Y. Wu, Carbon, 2016, 99, 35.

$23 \mathrm{X} . \mathrm{Yu}, \mathrm{H}$. Hu, Y. Wang, H. Chen and X. Lou, Angew. Chem., 2015, 54(25), 7395.

24 K. Chang, D. Geng, X. Li, J. Yang, Y. Tang, M. Cai, R. Li and X. Sun, Adv. Energy Mater., 2013, 3(7), 839.

25 X. Chen, K. Zhang, Z. An, L. Wang, Y. Wang, S. Sun, T. Guo, D. Zhang, Z. Xue, et al., Int. J. Hydrogen Energy, 2018, 43, 7326.

26 J. Li, Y. Hou, X. Gao, D. Guan, Y. Xie, J. Chen and C. Yuan, Nano Energy, 2015, 16, 10.

27 J. Deng, H. Li, J. Xiao, Y. Tu, D. Deng, H. Yang, H. Tian, J. Li, P. Ren and X. Bao, Energy Environ. Sci., 2015, 8(5), 1594.

28 J. Zabinski, M. Donley, S. Walck, T. Schneider and N. McDevitt, Tribol. Trans., 1995, 38(4), 894.

29 H. Jeong, J. Lee, W. Shin, Y. Choi, H. Shin, J. Kang and J. Choi, Nano Lett., 2011, 11(6), 2472.

30 H. Wang, T. Maiyalagan and X. Wang, ACS Catal., 2012, 2(5), 781.

31 P. Chen, J. Yang, S. Li, Z. Wang, T. Xiao, Y. Qian and S. Yu, Nano Energy, 2013, 2(2), 249.

32 G. Wang, X. Hu, L. Liu, Y. Yu, H. Lv and A. Chen, J. Mater. Sci.: Mater. Electron., 2018, 29, 5363.

33 S. Daia, Z. Liuc, B. Zhaob, J. Zengc, H. Hub, et al., J. Power Sources, 2018, 387, 43.

34 X. Wang, J. Ding, S. Yao, X. Wu, Q. Feng, Z. Wang and B. Geng, J. Mater. Chem. A, 2014, 2(38), 15958.

35 A. Sanger, V. K. Malik and R. Chandra, Int. J. Hydrogen Energy, 2018, 43(24), 11141-11149.

36 K. Huang, J. Zhang, G. Shi and Y. Liu, Electrochim. Acta, 2014, $132,397$.

37 J. M. Soon and K. P. Loh, Electrochem. Solid State Lett., 2007, 10(11), A250-A254. 